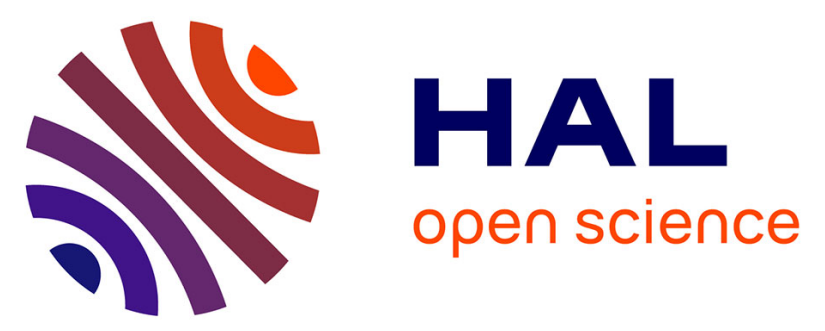

\title{
Decreased motivational properties of morphine in mouse models of cancerous- or inflammatory-chronic pain: implication of supraspinal NPFF2 receptors
}

\author{
Alexandre Betourne, Julien Familiades, Ludovic Lacassagne, Hélène Halley, \\ Martine Cazales, Bernard Ducommun, Jean-Michel Lassalle, Jean-Marie \\ Zajac, Bernard Frances
}

\section{To cite this version:}

Alexandre Betourne, Julien Familiades, Ludovic Lacassagne, Hélène Halley, Martine Cazales, et al. Decreased motivational properties of morphine in mouse models of cancerous- or inflammatorychronic pain: implication of supraspinal NPFF2 receptors. Neuroscience, 2008, 157 (1), pp.12-21. 10.1016/j.neuroscience.2008.08.045 . hal-00319865

\section{HAL Id: hal-00319865 https://hal.science/hal-00319865}

Submitted on 9 Sep 2008

HAL is a multi-disciplinary open access archive for the deposit and dissemination of scientific research documents, whether they are published or not. The documents may come from teaching and research institutions in France or abroad, or from public or private research centers.
L'archive ouverte pluridisciplinaire HAL, est destinée au dépôt et à la diffusion de documents scientifiques de niveau recherche, publiés ou non, émanant des établissements d'enseignement et de recherche français ou étrangers, des laboratoires publics ou privés. 


\section{Neuroscience}

\section{Title:}

Decreased motivational properties of morphine in mouse models of cancerous- or inflammatory-chronic pain: implication of supraspinal $\mathrm{NPFF}_{2}$ receptors.

\section{Authors:}

Alexandre BETOURNE ${ }^{(1,2)}$, Julien FAMILIADES ${ }^{(1,2)}$, Ludovic LACASSAGNE ${ }^{(1,2)}$, Hélène $\operatorname{HALLEY}^{(1,2)}$, Martine CAZALES ${ }^{(3)}$, Bernard DUCOMMUN $^{(3)}$, Jean-Michel $\operatorname{LASSALLE}^{(1,2)}$, Jean-Marie ZAJAC $^{(4)}$ and Bernard FRANCES ${ }^{(1,2)}$.

\section{Laboratory:}

(1) Université de Toulouse, Centre de Recherches sur la Cognition Animale

${ }^{(2)}$ CNRS - UMR 5169, Université Paul Sabatier, UFR SVT Bat 4R3b3, 118 route de Narbonne 31062 Toulouse, France.

(3) Université de Toulouse, Laboratoire de Biologie Cellulaire et Moléculaire du Contrôle de la Prolifération, CNRS-UMR 5088, Université Paul Sabatier, bat 4R3 118 route de Narbonne 31062 Toulouse, France.

(4) Université de Toulouse, Institut de Pharmacologie et Biologie Structurale, CNRS-UMR 5089, 205 route de Narbonne, 31077 Toulouse, France. 


\section{Corresponding author:}

Bernard FRANCES, Centre de Recherches sur la Cognition Animale, CNRS UMR 5169, Bât 4R3 b3, Université Paul Sabatier, 118 route de Narbonne, 31062 Toulouse Cedex 4, France. Phone: +33 5615563 36. Fax: +33 5615561 54. E-mail: frances@cict.fr

Running Title: Inhibition of morphine-induced place preference during cancer pain.

Section Editor: Dr. Geoffrey Schoenbaum 


\begin{abstract}
Our main purpose was to evaluate the influence of cancer pain on the rewarding properties of morphine. Opioids are very addictive when used by healthy persons, conversely the occurrence of an opioid addiction seems very low when patients suffering from cancer are treated with morphine. We investigated the reinforcing properties of morphine in the place preference paradigm on a new model of mice suffering from a cancer pain induced by syngenic melanoma cells injected in the hind paw. These data were compared with mice suffering either from a short-term- or a chronic- inflammatory pain induced respectively by injection of carrageenan or Complete Freund's Adjuvant. Remarkably, mice suffering from cancer pain or chronic inflammatory pain did not develop any preference for the environment associated with the injection of morphine. In mice injected with melanoma cells, the specific binding of $\left[{ }^{125} \mathrm{I}\right] \mathrm{EYF}$, an agonist of NPFF 2 receptors, was increased in several brain areas involved in the rewarding properties of opiates, including the shell of the nucleus accumbens, the major islands of Calleja, the ventral endopiriform nucleus and the amygdaloid area. Our study is the first to reveal a modification of morphine rewarding properties under cancer pain in rodents. We postulate that anti-opioid neuropeptides might contribute to the suppression of morphine rewarding effects in this murine model of cancer pain.
\end{abstract}

Key words: Neuropeptide FF, reward, Conditioned Place Preference, morphine, cancer pain, inflammatory pain. 
Abbreviations:

Main text:

CA1, Cornu Ammonis 1 of hippocampus; CFA, Complete Freund's adjuvant; CPP, Conditioned Place Preference paradigm; DSM-IV, Diagnostic and Statistical Manual Revision 4; ERK, extracellular regulated kinase; [ $\left.{ }^{125} \mathrm{I}\right] \mathrm{EYF},\left[{ }^{125}\right] \mathrm{EYWSLAAPQRF-} \mathrm{NH}_{2}$; GRK2, G-protein-coupled receptor kinase 2; NPFF, Neuropeptide FF; NPFF 2 , NPFF receptor 2; RF9, selective NPFF receptor 2 antagonist.

Autoradiography:

Aa, amygdaloid area; AcbC, core of the nucleus accumbens; AcbSh, shell of the nucleus accumbens; CG, central gray substance of midbrain; EPI, external plexiform layer of the olfactory bulb; $\mathrm{Hb}$, habenular nucleus; ICj, islands of Calleja; ICjM, major islands of Calleja; LSt, lateral striatal stripe; PP, peripeduncular nucleus; PtN, pretectal nucleus area; Re, reuniens thalamic nucleus; SuG, superficial gray layer of the superior colliculus; Ven, ventral, endopiriform nucleus; VMH, ventromedial hypothalamic nucleus; VTT, ventral tenia tecta. 
Opiates are the choice analgesics for the treatment of chronic pain and are thus currently administered to patients experiencing cancer-related pain. However, a better use of opiate-based analgesics is warranted and will require more knowledge on the physiopathological changes induced by prolonged opioid therapies. As improvements in cancer diagnosis and treatments have extended the life expectancy of cancer patients, attention must also be focused on increasing quality of life. Indeed, approximately 30 $50 \%$ of all cancer patients experience moderate to severe pain, and $75-95 \%$ of patients at advanced-stage or with metastatic cancer, experience substantial life-altering cancerinduced pain (Mercadante, 2001, Mantyh et al., 2002). Morphine and its derivatives are commonly thought not to cause major tolerance and physical or psychological dependence when appropriately used in clinic (for example see Sallerin-Caute et al., 1998). However, for long term treatments, this assertion remains highly controversial as pointed out by Savage, 1996, and more recently reviewed by Ballantyne and LaForge (2007). In fact, up to now there is no neurobiological hypothesis able to explain the lack of a physical and even more of a psychological dependence on opiates in cancer patients.

An obstacle to develop new treatments for persisting cancer pain and/or optimally coordinating existing treatments is the paucity of knowledge on the basic neurobiology of cancer pain. Although it shares many features with inflammatory and neuropathic pain (Mantyh et al., 2002), cancer induces a unique pain condition (Honore et al., 2000). Over the years, animal models of cancer pain have been helpful in demonstrating the distinct pharmacological and neurochemical aspects of cancer pain, suggesting an inflammatory, neuropathic and also tumorigenic component (Mantyh, 2004). Among the few accepted animal models, a murine model of bone cancer pain, quite difficult to 
develop, has been informative (Schwei et al., 1999, Wacnik et al., 2001, Menendez et al., 2003). Recently, a mouse model of cancer pain induced by orthotopic inoculation of B16 melanoma cells in the hind paw of syngenic C57BL/6J mice has been developed (Sasamura et al., 2002, Mao-Ying et al., 2006).

In our study, we aimed to evaluate the reinforcing activity of morphine in this cutaneous cancer pain model. These animals were compared with control C57BL/6J mice and animals with a short-term or a chronic inflammatory pain (induced respectively by an injection of carrageenan or Complete Freund's Adjuvant in the hindpaw). We chose the widely used Conditioned Place Preference paradigm (CPP) to assess the rewarding properties of the opiate (Tzschentke, 1998, Bardo and Bevins, 2000, Tzschentke, 2007). In this procedure, after repeated association of a neutral context with the administration of a drug with motivational properties, the neutral context will acquire, during the course of conditioning, secondary motivational properties. Thus, when the animal is subsequently given the choice between two environments, the context formerly associated with the drug will elicit its preference. This associative property makes the CPP paradigm an adapted tool for testing newly developed compounds that might be useful for heroin or alcohol relapse prevention.

Several elements reviewed by Ronson (2004), indicate that a stress-system is activated in response to cancer. We hypothesized that an up-regulation of anti-opioid systems during cancer pain could counteract the effects of morphine and prevent the development of an addiction. Dynorphin, Cholecystokinin, Orphanin Q and Neuropeptide FF are distinct categories of neurotransmitter systems acting as modulators of endogenous opioid functions. Neuropeptide FF (FLFQPQRFamide, NPFF), is representative of a family of mammalian amidated neuropeptides whose precursors, 
pro-NPFF $A$ and pro-NPFF $B$ and $G$ protein-coupled receptors, $\mathrm{NPFF}_{1}$ and $\mathrm{NPFF}_{2}$, have been cloned (Kersante et al., 2006). Although the functional roles of NPFF and related endogenous peptides remain to be fully understood, NPFF peptides play an important role in the modulation of pain and could act as endogenous anti-opioids in rodents (Roumy and Zajac, 1998, Zajac, 2001). Furthermore, several experiments suggest that NPFF could participate in morphine tolerance and dependence. This peptide is able to produce some signs of withdrawal syndrome in morphine-dependent rats (Malin et al., 1990) and might participate in the development of morphine tolerance (Gelot et al., 1998). In addition, we showed recently that $1 \mathrm{DMe}$, an $\mathrm{NPFF}_{2}$ agonist, dose-dependently inhibits the reinforcing effects of morphine in the CPP paradigm (Marchand et al., 2006). The present study was therefore designed to examine the modifications of morphine motivational properties during cancer or inflammatory pain, and investigate whether these behavioral processes could be correlated at the molecular level by a variation of supraspinal $\mathrm{NPFF}_{2}$ receptors density. 


\section{Experimental procedures}

Animals and surgery

A total of 58 female C57BL/6J mice (6 to 8 weeks old, Iffa Credo, France) were used. They were housed in groups of three to five per cage in a temperature-controlled room $\left(21 \pm 1^{\circ} \mathrm{C}\right)$ subjected to a 12-hours light-dark cycle, with lights on at 8 a.m. Food and water were available ad libitum throughout the experiments.

Animal surgery and experimentation are authorized by the French Direction of Veterinary Service to $A B, B F, J M L$ and $J M Z$. The study was approved by The French Animal Care and Use Committee (Comité régional d’Ethique pour l'expérimentation animale Midi Pyrénées, ref MP 02/02/02/06). Experiments were performed in accordance with the guidelines for the Care and Use of Laboratory Animals and the Ethical guidelines for investigations of experimental pain in conscious animals (Zimmermann, 1983) and the European Communities Council Directive of November 24 $1986(86 / 609 / E E C)$.

\section{Drugs}

Morphine hydrochloride was obtained from Francopia (Gentilly, France). Complete Freund's adjuvant (CFA, heat killed Mycobacterium tuberculosis in $85 \%$ paraffin oil and $15 \%$ mannide monoleate), Carrageenan $\lambda$ type IV solution, Bovine serum albumin (BSA) and bestatin were from Sigma (France). 
Place conditioning (For further details see Marchand et al., 2006).

Apparatus: the Conditioned Place Preference (CPP) apparatus was divided into two identical-sized compartments (white and black), connected by a narrower one (grey). The floors were divided into squares to quantify the horizontal locomotion by counting the number of crossings.

Pre-conditioning (Day 0): Behavioral testing started one day before the tumor inoculation or the injection of Carrageenan or CFA. The animals were placed in the central compartment and had free access to the entire apparatus during 20 minutes. The time spent in each compartment was measured as the pre-drug preference. A mouse that had spent more than $66 \%$ of the time in the same compartment was excluded from the tests in order to follow the unbiased procedure version of the CPP paradigm.

Conditioning: Drug treatment $(\mathrm{NaCl}$, morphine) and side presentation (black or white) were randomly attributed to each mouse. The conditioning lasted three days (Day 1 to Day 3) with two sessions daily. Morphine $10 \mathrm{mg} \cdot \mathrm{Kg}^{-1}$ or $\mathrm{NaCl} 0.9 \%$ were given on alternate sessions. Animals received intraperitoneal morphine or $\mathrm{NaCl}$ administration then five minutes later, were confined to one compartment during 20 minutes. The compartment assignment procedure between saline and morphine groups was counterbalanced.

Test (Day 4): Following conditioning, place preference was determined on Day 4, in the same conditions as in the pre-conditioning test. 
Nociceptive models

Short-term inflammatory pain

Mice were injected with $30 \mu$ of a $4 \%$ Carrageenan $\lambda$ type IV solution diluted in $0.9 \%$ saline, subcutaneously in the intraplantar surface of the right or left hind paw randomly. After 4 hours, this produces an inflammatory pain lasting for about 48 hours. Carrageenan injections were given in the morning of Day 1, 4 hours before the first conditioning session.

\section{Long-term inflammatory pain}

Mice were injected with $30 \mu \mathrm{l}$ of Complete Freund's Adjuvant (CFA, 1mg/ml) 100\% solution subcutaneously in the intraplantar surface of the right or left hind paw. After one hour, through an immunologic reaction, this injection produces an inflammatory pain lasting for at least two weeks. CFA injections were given 72 hours before the first conditioning session (Day 1).

\section{Chronic tumorogenic pain}

B16-F0 cells, a highly invasive variant of B16 melanoma cells derived from C57BL/6J mouse was used (Fidler, 1975). B16-F0 melanoma cells were grown as monolayer cultures in GIBCO essential medium containing $10 \%$ fetal bovine serum, $4 \mathrm{mmol} / \mathrm{I}$ glutamine and $100 \mu \mathrm{g} / \mathrm{ml}$ Penicillin/Streptomycin. The melanoma cells suspended in sterile $\mathrm{NaCl} 0.9 \%\left(10^{7}\right.$ cells per $\left.\mathrm{ml}\right)$ were injected subcutaneously in the intraplantar surface of the right or left hind paw in a volume of $30 \mu$. Tumor was inoculated approximately 20 days before the first conditioning session, so that mice presented an 
ongoing marked hyperalgesia starting around Day 14 post-inoculation (Sasamura et al., 2002).

Measurements of mice paw volume

To assess the extent of the oedema or the tumor growth in situ, the volume of the glabrous region of the hind paw was plethysmographically determined (Lence plethysmometer, Ugo Basile ${ }^{\circledR}$, Comerio, VA, Italy). Data were expressed in milliliters as the difference between the right and left paws.

\section{Nociceptive tests}

Three previously validated models of inflammatory and cancer pain in mice (Henriques et al., 1987, Honore et al., 2000, Sasamura et al., 2002) were chosen. Pre-experiments were performed to adapt these models in our laboratory and confirm the time course of spontaneous pain arrival and hyperalgesia. As we intended to study the behavior of mice, stressful nociceptive tests such as the tail flick or the hot-plate test were incompatible with our experiments. It should be noted that, as pointed by Sasamura et al. (2002), mechanical stimulation (von Frey or pressure tests) of the paw in tumorbearing mice at advanced stages of tumor development is not acceptable since these tests wound the animals and elicit bleeding from the melanoma. Spontaneous pain was evaluated by adaptation of the non invasive method from Sufka et al., (1998): mice behavior was visually assessed during conditioning in the non drug associated compartments (i.e. after saline injection) and during the final test on Day 4. The frequency of hind paw lickings was counted throughout place preference experiments as 
an indicator of pain (Dubuisson and Dennis, 1977, Sufka et al., 1998, Menendez et al., 2003).

\section{Locomotion}

Simultaneously, horizontal locomotor activity was determined by the number of crossings of the lines drawn on the floor of the compartments during pre-conditioning, conditioning sessions on Day 1 and during the final test.

\section{Quantitative NPFF 2 Receptor Autoradiography}

These experiments were performed according to previous studies (Gouarderes et al., 2001, Gouarderes et al., 2002). Briefly, $\left[{ }^{125}\right.$ I]EYF (EYWSLAAPQRF-NH $\mathrm{N}_{2}$ ), a specific radioligand for NPFF2 receptors, was obtained by iodination of EYWSLAAPQRF-NH ${ }_{2}$ (EYW-NPSF). The specific activity was assumed to be that of ${ }^{125} \mathrm{I}-\mathrm{Na}(80.5 \mathrm{TBq} / \mathrm{mmol}$, $2175 \mathrm{Ci} / \mathrm{mmol}$, Amersham, France). Two days after the test (Day 6), the brains were removed rapidly, frozen in dry-ice-cooled 2-methylbutane, and stored at $-80{ }^{\circ} \mathrm{C}$. Rostrocaudal coronal sections (20 $\mu \mathrm{m}$ thick) were cut throughout forebrain to hindbrain regions in a cryostat microtome (Microm, France) at $-17^{\circ} \mathrm{C}$, mounted on gelatinchrome-alum-coated microscope slides and stored at $-80^{\circ} \mathrm{C}$.

Slides were brought to room temperature, preincubated in $50 \mathrm{mM}$ Tris- $\mathrm{HCl}$ buffer $(\mathrm{pH}$ 7.4) followed by two washes in fresh $50 \mathrm{mM}$ Tris- $\mathrm{HCl}$. Sections were incubated at $25^{\circ} \mathrm{C}$ with [ ${ }^{125}$ I]EYF $\left(0.05 \mathrm{nM}\right.$ (approximately $\left.\left.0.8 K_{\mathrm{D}}\right), 150 \mathrm{~min}\right)$ in $50 \mathrm{mM}$ Tris- $\mathrm{HCl}$ buffer $(\mathrm{pH}$ 7.4) containing $0.1 \% \mathrm{BSA}, 25 \mu \mathrm{M}$ bestatin and $60 \mathrm{mM} \mathrm{NaCl}$. Nonspecific binding was determined by addition of $1 \mu \mathrm{M}$ NPFF to the incubation medium using adjacent additional sections. Slides were subsequently washed and dried under a stream of cold 
air, then placed in contact with a Phosphoscreen imaging plate (Amersham) for 5 days. The exposed imaging plate was scanned with a Storm 860 imager reader (Molecular Dynamics) with a $50 \mu \mathrm{m}$ resolution. The corresponding density was quantified and expressed as PSL/pixel (photo-stimulated luminescence/pixel). After exposition, the slides were stained with cresyl violet and visually compared with autoradiographic images and the mouse atlas of Franklin and Paxinos, (1997). Each anatomical structure was measured bilaterally in as many sections as possible from each animal. Nonspecific labeling in the presence of $1 \mu \mathrm{M}$ NPFF was subtracted from all readings to provide quantitative measurements of specific binding. Data were pooled for statistical analysis and are represented as the mean \pm S.E.M. per region.

\section{Data analysis}

Values are expressed as mean $+/-$ SEM.

The time (sec) spent by each group of animals in the drug-paired and the $\mathrm{NaCl}$ associated compartment on Day 0 was compared by a paired Student's t-test to verify that we used a non biased procedure. The time (sec) spent by each group in the drugpaired compartment on Day 0 and Day 4 was compared by a paired Student t-test to assess the existence of place preference (or aversion). For each group, the horizontal locomotor activity was compared after $\mathrm{NaCl}$ injection and after morphine injection, with a paired Student t-test. The differences in horizontal activity between groups after injection of $\mathrm{NaCl}$ or morphine were compared by an ANOVA. Alpha levels were set at $\mathrm{P}<0.05$ for all tests.

Densities of $\mathrm{NPFF}_{2}$ binding in brain regions were compared for the different groups by a two-way analysis of variance (ANOVA). Post hoc comparisons using Fisher's least 
significant difference (LSD) test are indicated in the text. Alpha levels were set at $P<$ 0.05 for all tests. 


\section{Results}

Oedema and Tumor growth

After the initial carrageenan injection, the oedema increases rapidly and reaches its acme four hours later $(0.05+/-0.006 \mathrm{ml}, \mathrm{n}=10)$. Then, the resorption is slow and sometimes incomplete with a cicatricial wound at the end of behavioral testing (approximately 72 hours after the initial injection, Figure 1a). In contrast, CFA produces an inflammation beginning one hour after injection in the paw, with an oedema peaking between 4 and 8 hours $(0.06+/-0.005 \mathrm{ml}, 8$ hours after the injection, $n=9)$, with an average increase of $0.07+/-0.005 \mathrm{ml}$ during behavioral experiments and lasting over two weeks $(0.11+/-0.004 \mathrm{ml}$, on Day 13). The melanoma became apparent as a black nodule around Day 8 after inoculation. Thereafter, the paw volume increased exponentially as a function of time until the animals were sacrificed for autoradiography. Tumor-bearing mice were tested for place conditioning between Day 21 and 25 postinoculation. The volume of the inoculated paw was $0.18+/-0.04 \mathrm{ml}, \mathrm{n}=10$ on Day 25 (Figure 1a, 1b). Importantly, mice that had been inoculated with cancer cells or vehicle, exhibited no overt decrease in body weight throughout the 21 days observation period post-injection (mean weight on the first day of conditioning $19.7+/-0.39 \mathrm{~g} v s 18.8+/$ $0.74 \mathrm{~g}$ for cancer and control mice, respectively).

Nociceptive Behavior

We assessed mice spontaneous pain behaviour by counting the hind paw lickings. Spontaneous pain behaviour:

Control mice never showed any signs of pain whereas mice from the three other groups licked their paw throughout the entire place conditioning experiments, indicating an 
elevated pain state (see Figure 2). Carrageenan produces a spontaneous pain appearing as soon as 4 hours after the initial injection, but short-lasting, as indicated by the number of paw lickings being maximum during the first day of conditioning $(10.2+/-$ 2.7 lickings on Day1), but nearly absent on the test day $(0.9+/-0.7$ on Day 4$)$. CFAinduced spontaneous pain is less intense 4 hours post injection with $4.7+/-1.1$ lickings, but longer-lasting. These mice licked their paws $3.1+/-0.9$ times on the first day of conditioning and $1.6+/-0.5$ times during the final test session (on Day 4) with an average of $2.8+/-0.9$ lickings during the 4 days of behavioral testing. Melanomainoculated mice licking count parallels the observations made in the CFA-treated mice with an apparently more intense persistent pain, as indicated by an average of $4+/-1$ paw lickings throughout the place conditioning experiments. Remarkably, in the CFA or cancer groups, mice never exhibit a licking score as high as the peak observed for the carrageenan-injected ones (see Figure 2).

\section{Locomotion}

We used a measure of the horizontal locomotor activity as an indirect indicator of pain. On the first day of conditioning (Day 1), there is a statistically significant variation for locomotion among the four groups (Anova, $F(3,39)=15.927, p<0.001, R^{2}=0.551$; Figure 3a). LSD post-hoc analysis revealed that 4 or 8 hours after carrageenan injection, mice locomotor activity in absence of morphine is significantly reduced $(p<0.001$, vs $\mathrm{NaCl}-$ injected mice). CFA-treated mice present the same reduction $(p=0.001$ vs $\mathrm{NaCl})$, confirming the induction of inflammatory pain. The locomotor activity of tumor-inoculated mice is also significantly impaired in comparison with control animals $(p=0.007)$. In carrageenan-treated mice, horizontal activity is significantly lower than the locomotion in 
CFA and cancer groups ( $p=0.015$ vs CFA, $p<0.001$ vs Cancer). Thus, a decrease in locomotion parallels the course of spontaneous paw lickings in the pain groups.

Morphine administration on Day 1 increased the locomotor activity of the four experimental groups, showing the well-known morphine-induced hyperlocomotion effect. In comparison with the activity measured in the absence of morphine on Day 1, after morphine injection, the locomotion of the control and carrageenan groups was increased 3.19- and 4.61- fold, respectively. In contrast, the horizontal activity of CFA and cancer mice was only increased 1.83- and 1.53- fold after morphine injection (Figure 3a). It is likely that the mechanism of hyperlocomotion is distinct from that of analgesia and may, in and of itself, be a strong internal stimulus that opposes inhibition of motor activity due to enhanced nociceptive signaling from the inflammation or injury. The previously described analgesic effect consecutive to the injection of morphine $\left(10 \mathrm{mg} \cdot \mathrm{kg}^{-1}\right)$ was confirmed by the strong reduction of mean hindpaw lickings on Day 1 in the three pain groups (data not shown). Thus, the reduced locomotor score levels in the pain groups after morphine administration might be partly explained by a mechanical limitation due to the increase of the hindpaw volume and associated impaired motor coordination.

On the test day (Day 4; Figure 3b) mice locomotion was slightly but significantly reduced in the three groups of suffering mice in comparison to $\mathrm{NaCl}$-injected mice (Anova $\mathrm{F}(3,41)=2.893, p=0.047, \mathrm{R}^{2}=0.175$, followed by a post-hoc LSD analysis $(\mathrm{NaCl} v s$ Carrageenan, $p=0.018 ; \mathrm{NaCl}$ vs $\mathrm{CFA}, p=0,024 ; \mathrm{NaCl}$ vs Cancer, $p=0.007)$. There was no significant difference in locomotion between Carrageenan, CFA or cancer groups. Nevertheless, in our three pain models, locomotion on Day 4 was not statistically modified in comparison with Day 0 (carrageenan, $F(1,32)=1.915, p=0.176, R^{2}=0.056$; CFA, $F(1,14)=2.972, p=0.107, R^{2}=0.175 ;$ cancer, $\left.F(1,26)=2,171, p=0.153, R^{2}=0.077\right)$ 
whereas control mice presented a significant increase in horizontal activity on Day 4 $\left(F(1,10)=6.472, p=0.029, R^{2}=0.393\right)$. This signs an expected activity rebound usually observed on the test day in the CPP paradigm, reduced in mice under inflammatory pain, and absent in the cancer group (Figure 3b).

\section{Conditioned Place Preference}

According to our unbiased CPP protocol, mice included in the different experimental groups did not show any preference for the forthcoming drug-associated compartment during pre-conditioning. Indeed, for each group included in this study, the comparison of the time spent in the drug-paired compartment versus the $\mathrm{NaCl}$-paired compartment did not show any differences [paired Student t-Test: $\mathrm{NaCl}, p=0.966, \mathrm{n}=12$; Carrageenan, $p=0.165, \mathrm{n}=16$; CFA, $p=0.354, \mathrm{n}=8$; Cancer, $p=0.158, \mathrm{n}=14]$. As illustrated by Figure 4, on the test Day (D4), control mice spent significantly more time in the morphineassociated compartment [paired Student's t-test, $p=0.003$ ]. Mice which underwent shortterm inflammatory pain after carrageenan injection also preferred the compartment where they had received the opiate [ $p=0.030]$. Although slightly reduced, the level of place preference displayed by the carrageenan group was not statistically different from the control group (one-way ANOVA, $p=0.246$ ). Mice suffering from chronic inflammatory pain (CFA inflicted) or cancer pain did not show any preference for the morphine-intake associated side [CFA, $p=0.178$; cancer, $p=0.497$ ]. In conclusion, we found that the place preference induced by morphine administration was suppressed during both chronic inflammatory pain and cancer pain, but remained unchanged during short-term inflammatory pain induced by carrageenan injection. In order to characterize this phenomenon at the molecular level, we investigated if a modification of the NPFF 
system, a peptide with known anti-opioid properties, could underlie the reduction of morphine rewarding properties during cancer pain.

\section{$\mathrm{NPFF}_{2}$ receptor binding}

We aimed to evaluate the density of $\mathrm{NPFF}_{2}$ receptors in animals that received morphine under cancer pain with animals that received morphine without pain. Therefore, the binding density of $\mathrm{NPFF}_{2}$ receptors was investigated on morphine-injected animals: mice suffering from cancer pain were compared with mice undergoing short-lasting carrageenan-induced pain and control non-suffering animals (see Figure 5 and Figure 6). $\left[{ }^{125} \mathrm{I}\right] \mathrm{EYF}$ binding, a radioligand selective for $\mathrm{NPFF}_{2}$ receptors, was differentially distributed throughout the brain whereas nonspecific binding was relatively homogeneous and remained barely above the background level. The mean specific binding of $\left[{ }^{125} \mathrm{I}\right] \mathrm{E}$ YF in all regions reached $90 \%$. An heterogeneous but high density of $\left[{ }^{125}\right]$ EYF binding was observed in several brain regions. Among these structures, the specific binding of $\left.\left[{ }^{125}\right]\right] E Y F$ to $\mathrm{NPFF}_{2}$ receptors was significantly increased by carrageenan inflammation in the ventral tenia tecta and the ventral endopiriform nucleus ( $p=0.034$ and $p=0.014$ vs controls). We also found a more pronounced increase in the habenular nucleus, the peripeduncular nucleus and the amygdaloid area $(p=0.005$, $p=0.0001$ and $p=0.0001$ vs controls). Conversely, $\left[{ }^{125} \mathrm{I}\right] \mathrm{EYF}$ binding was substantially decreased in the external plexiform layer of the olfactory bulb $(p=0.046)$.

In mice injected with melanoma cells, the specific binding of $\left[{ }^{125} \mid\right] E Y F$ was also increased in the ventral endopiriform nucleus $(p=0.028)$ and in the amygdaloid area $(p=$ $0.0001)$. In contrast, $\left[{ }^{125}\right.$ I]EYF binding remained at control levels in the ventral tenia tecta and in the habenular and peripeduncular nuclei. Two other regions presented a specific 
increase in cancer mice, the major islands of Calleja $(p=0.026)$ and, very interestingly, the accumbens nucleus: the increase was modest in the core region but reached significance in the shell region $(p=0.037)$. 


\section{Discussion}

The common idea that morphine administration in humans under chronic pain does not lead to addiction is still debated. In the literature, most papers refer to a seminal epidemiologic study published by (Porter and Jick, 1980) later on confirmed by others (Evans, 1981). Nonetheless, a growing amount of recent reports indicates a "problematic opioid use" in patients who deviate from their prescribed program of opioid treatment and exhibit an opioid-seeking behaviour that does not meet all the DSM-IV criteria for true addiction (Furlan et al., 2006, Ballantyne and LaForge, 2007). In addition, pain management in patients with a history of substance abuse is a great challenge (Friedman et al., 2003, Passik et al., 2006). A better understanding of the neurobiological basis of reward modifications under chronic pain will give help in improving pain alleviation during long term diseases requiring a morphine treatment.

In order to evaluate experimentally a possible modification of morphine reinforcing properties in animals under pain, we used a model of cancer and two models of inflammatory pain. We found a complete suppression of the motivational properties of morphine in the cancer pain group. Place preference was also abolished in mice under chronic inflammatory pain while the reinforcing effects of morphine were unchanged in the semi-chronic inflammatory pain model.

Previous studies in rats have found a significant reduction of morphine reinforcing properties in animals undergoing carrageenan or formalin hyperalgesia. This effect disappeared over time in conjunction with the reduction of inflammatory pain (Suzuki, 2001). Unexpectedly, in our study, mice with a paw inflammation induced by carrageenan developed a mild place preference for morphine. This discrepancy could be best explained by the differential time course of pain throughout behavioural measures. 
Here, on the last day of conditioning, spontaneous pain was greatly reduced or even abolished in carrageenan-treated mice. Therefore, in this group, some mice may have received a morphine injection while in a "suffering" state close to control animals. Nonetheless, our results do not confirm the absence of morphine rewarding effects observed in rats under short-lasting inflammatory pain. In past studies using rats injected with CFA into the hind paw, a longer lasting model of inflammatory pain, place preference to morphine has been observed (Shippenberg et al., 1988, Sufka, 1994). In contrast, we found that mice which suffered an ongoing inflammatory pain did not develop any significant place preference to morphine. Finally, our main objective was to study the motivational properties of morphine under a specific model of chronic pain, i.e cancer pain. We chose the model of orthotopic syngenic grafts originally developed by (Sasamura et al., 2002) and we confirmed in preliminary experiments the presence of an early onsetting thermal hyperalgesia (data not shown). In these mice, the place preference was completely abolished, which represents, to our knowledge, the first experimental evidence for a suppression of morphine rewarding properties during cancer pain in an animal model.

Altogether, these results indicate that complex neurobiological processes develop in the course of chronic cancer and inflammatory pain and interact negatively with morphine reward. Obviously, modifications of the central endogenous opioid system during pain experience might modulate the reinforcing properties of opiates. Indeed, in mice with a partial sciatic nerve ligation, a model of chronic neuropathic pain, place preference is also suppressed. At the cellular level, this phenomenon was associated with a reduction of morphine-induced dopamine release in the nucleus accumbens (Acb), a desensitization of mu opioid receptors, an upregulation of the receptor kinase 
GRK2 and a possible reduction of phosphorylated ERK and P38 in dopaminergic ventral tegmental area neurons (Ozaki et al., 2002, Ozaki et al., 2003, Ozaki et al., 2004, Narita et al., 2007). A similar reduction of morphine-induced dopamine release was found in the limbic forebrain of rats under short-term inflammatory pain and was counteracted by the microinjection of dynorphin A antibodies in the Acb (Narita et al., 2005). Besides, administration of the kappa opioid receptor antagonist nor-BNI dose-dependently prevented the reduction of morphine rewarding effects in rats under inflammatory pain (Suzuki et al., 1999). These experiments suggest that a sustained activation of the kappa opioid system in the Acb was responsible for the suppression of morphine reward in the CPP and strengthen the status of dynorphin as a central opiate modulator. Alongside, we recently reported that a Neuropeptide FF analogue counteracts the reinforcing properties of opiates (Marchand et al., 2006). Thus, we hypothesized that this system might be implicated in the modification of morphine rewarding effects during chronic pain.

The distribution of NPFF receptors in the supraspinal brain of C57BL/6J mouse has been previously studied in details (Gouarderes et al., 2004b). The variations of NPFF 2 receptors density in the course of chronic pain have also been studied in rats. Expression of $\mathrm{NPFF}_{2}$ transcript in the rat dorsal spinal cord was increased by carrageenan inflammation of the hind paw (Yang and ladarola, 2003), a result consistent with increased $\mathrm{NPFF}_{2}$ binding in the spinal cord of rats with tibio-tarsal joint inflammation induced by CFA (Lombard et al., 1999). Central NPFF 2 mRNA content was also increased in a colonic inflammation model and a neuropathic pain model, but was restricted to the brainstem (Nystedt et al., 2004). In contrast, both NPFF and NPFF 2 
mRNAs were transiently up-regulated in the spinal cord, but remained unmodified in the brainstem of rats with a carrageenan-induced inflammation (Nystedt et al., 2004, Yang and ladarola, 2006).

In this study, we investigated a possible modification of $\mathrm{NPFF}_{2}$ binding in mice with short-term inflammatory pain and mice with cancer pain. Unexpectedly, no changes in the density of $\mathrm{NPFF}_{2}$ receptors have been found in the Central Gray (CG), a major brain region involved in pain transmission. An interesting result is the increase of $\mathrm{NPFF}_{2}$ binding in the amygdaloid area of carrageenan and cancer mice. The amygdala is a key structure in the regulation of anxiety and contains high levels of endogenous opioids. Moreover, there have been many reports on the relation between pain and emotion, and the co-morbidity between chronic pain and depression is high. Accordingly, in the rat amygdala, Narita et al. found a desensitization of $\mathrm{mu}$ and delta receptors during neuropathic and CFA inflammatory pain while kappa receptors where upregulated only after CFA injection (Narita et al., 2006). Although these modifications may participate in the development of anxiety during pain experiences, results in our team (V. Marty, unpublished observations) and others (Kotlinska et al., 2007) suggest that NPFF does not play a major role in anxiety modulation. Thus, the increase observed here indicates a more complex action on reward experience during pain, such as increased pain sensitivity or decreased morphine reinforcement, at least in the cancer group.

Several structures belonging to the olfactory system also displayed an elevated $\mathrm{NPFF}_{2}$ binding level: the ventral endopiriform nucleus in the two pain groups and the ventral tenia tecta in carrageenan-treated mice only. The ventral endopiriform nucleus is most probably involved in the regulation of cortical plasticity in olfactory areas, and may indirectly relay olfactory information to the VTA (Kowianski et al., 2004, Geisler and 
Zahm, 2006). The ventral tenia tecta is a secondary olfactory structure connected to the CA1 region of the hippocampus (Cenquizca and Swanson, 2007), likely involved in the construction of olfactory associative memories (Brunjes et al., 2005). Therefore, our results suggest a modulation of olfactory reward by NPFF. Olfactory information is a key stimulus for reward-related behaviours in rodents, and the VTA has been shown to be activated in response to olfactory cues. As our CPP protocol did not implicate specific olfactory cues, it is unclear whether NPFF regulates direct olfactory information or is part of a more complicated reward circuitry involving a distinct specific action (i.e. associative) of the olfactory system.

$\mathrm{NPFF}_{2}$ binding was specifically increased in the interconnected habenular and peripeduncular nuclei of the carrageenan group. Interestingly, the habenula $(\mathrm{Hb})$ receives inputs from the nucleus accumbens, sends major projections to the VTA and has been involved in anxiety, stress, pain and reward (Kimura et al., 2007). In addition, during repeated morphine administration, the habenulo-interpeduncular pathway has been shown to modulate dopamine release in the Acb and consequently morphine sensitization (Taraschenko et al., 2007). Altogether, these studies suggest a possible modulation of the reinforcing properties of morphine by the NPFF system in the $\mathrm{Hb}$ during inflammatory pain. As suggested by the mild place preference developed in the carrageenan group, such a modulation is expected to have only a limited influence on the rewarding properties of morphine.

Finally, NPFF 2 binding was specifically increased in the major islands of Calleja (ICjM) and the shell of the Acb of tumor-bearing mice. The obscure ICjM region is interconnected with the amygdaloid area, Acb and VTA (Fallon et al., 1978) and belongs to the olfactory tubercle, a structure implicated in morphine and cocaine reward 
(Kornetsky et al., 1991). Therefore, the ICjM may relay a very specific action of NPFF on reward modulation. The specific $\mathrm{NPFF}_{2}$ binding increase observed in the Acb further supports the hypothesis of a direct modulation of morphine rewarding effects by this neuropeptide during chronic cancer pain. Indeed, the Acb shell appears to be specifically involved in the rewarding properties of drugs of abuse whereas the core region is required for maintaining cue-elicited drug-seeking behaviour (Miller and Marshall, 2005). Opioid receptors in the VTA play a major role in opioid reward and place preference conditioning. Unfortunately, the VTA could not be included in this study because this region contains only a very low density of NPFF2 and NPFF1 receptors in C57BL/6J mice, near the limit of detection, as previously published in previous works of our team (Gouarderes et al., 2001, Gouarderes et al., 2004a, Gouarderes et al., 2004b). Hence, our results indicate an upregulation of the NPFF system in mice under sustained pain. According to the opioid homeostasis balance theory originally developed by (Roques, 2000), addiction may result from the rupture of an equilibrium between opioid and "anti-opioid' systems. Based on our findings, we propose that under chronic pain, the up-regulation of anti opioid peptides such as dynorphin, NPFF or cholecystokinin may counteract the reinforcing properties of morphine. Such a modulation of the NPFF system could participate to the reduction of morphine reward observed in the place preference paradigm. In order to confirm this hypothesis, a NPFF antagonist administered concomitantly with morphine should be able to restore the place preference for morphine in injured animals. Interestingly, RF9, a potent and selective NPFF receptor antagonist has been discovered very recently (Simonin et al., 2006), and shown to counteract NPFF anti-opioid effects on morphine analgesia (Fang et al., 2008). Our preliminary data suggest that RF9 has no rewarding or aversive effect by itself. 
Thus, this drug could be an interesting co-analgesic, provided that it would not increase morphine psychoactive effects. Although RF9 is yet incompletely characterized and binds equally to both $\mathrm{NPFF}_{1}$ and $\mathrm{NPFF}_{2}$ receptors, studies focusing on RF9 and novel antagonists with increased specificity will surely improve our knowledge of a putative involvement of the NPFF system in reward modulation during chronic pain. 


\section{Disclosure/Conflict of Interest}

None of the authors have any conflicts of interest to disclose relating to this submission. The authors declare that, except for income received from their primary employer, no financial support or compensation has been received from any individual or corporate entity over the past 3 years for research or professional service and there are no personal financial holdings that could be perceived as constituting a potential conflict of interest. 


\section{Acknowledgements}

This work was supported by The Ligue Nationale de Recherches Contre le Cancer, the Paul Sabatier University and the Centre National de la Recherche Scientifique. We would like to thank Doctor Claire Rampon and Doctor Laure Verret for helpful comments on the manuscript and Professor Anne Roussin for excellent advice on clinical addiction to opiates. 


\section{References}

Ballantyne JC, LaForge KS (2007) Opioid dependence and addiction during opioid treatment of chronic pain. Pain 129:235-255.

Bardo MT, Bevins RA (2000) Conditioned place preference: what does it add to our preclinical understanding of drug reward? Psychopharmacology 153:31-43.

Brunjes PC, Illig KR, Meyer EA (2005) A field guide to the anterior olfactory nucleus (cortex). Brain Res Brain Res Rev 50:305-335.

Cenquizca LA, Swanson LW (2007) Spatial organization of direct hippocampal field CA1 axonal projections to the rest of the cerebral cortex. Brain Res Rev 56:1-26.

Dubuisson D, Dennis SG (1977) The formalin test: a quantitative study of the analgesic effects of morphine, meperidine, and brain stem stimulation in rats and cats. Pain 4:161-174.

Evans PJ (1981) Narcotic addiction in patients with chronic pain. Anaesthesia 36:597-602.

Fallon JH, Riley JN, Sipe JC, Moore RY (1978) The islands of Calleja: organization and connections. J Comp Neurol 181:375-395.

Fang Q, Wang YQ, He F, Guo J, Guo J, Chen Q, Wang R (2008) Inhibition of neuropeptide FF (NPFF)-induced hypothermia and anti-morphine analgesia by RF9, a new selective NPFF receptors antagonist. Regul Pept 147:45-51.

Fidler IJ (1975) Biological behavior of malignant melanoma cells correlated to their survival in vivo. Cancer Res 35:218-224.

Franklin KBJ, Paxinos G (1997) The mouse brain in stereotaxic coordinates. Elsevier Academic Press, Amsterdam.

Friedman R, Li V, Mehrotra D (2003) Treating pain patients at risk: evaluation of a screening tool in opioid-treated pain patients with and without addiction. Pain Med 4:182-185.

Furlan AD, Sandoval JA, Mailis-Gagnon A, Tunks E (2006) Opioids for chronic noncancer pain: a meta-analysis of effectiveness and side effects. CMAJ 174:1589-1594.

Geisler S, Zahm DS (2006) Neurotensin afferents of the ventral tegmental area in the rat: [1] reexamination of their origins and [2] responses to acute psychostimulant and antipsychotic drug administration. Eur J Neurosci 24:116-134.

Gelot A, Frances B, Gicquel S, Zajac JM (1998) Antisense oligonucleotides to human SQAneuropeptide FF decrease morphine tolerance and dependence in mice. Eur $J$ Pharmacol 358:203-206.

Gouarderes C, Faura CC, Zajac JM (2004a) Rodent strain differences in the NPFF1 and NPFF2 receptor distribution and density in the central nervous system. Brain Res 1014:61-70.

Gouarderes C, Mollereau C, Tafani JA, Mazarguil H, Zajac JM (2001) [(125)I]EYF: a new high affinity radioligand to neuropeptide FF receptors. Peptides 22:623-629.

Gouarderes C, Puget A, Zajac JM (2004b) Detailed distribution of neuropeptide FF receptors (NPFF1 and NPFF2) in the rat, mouse, octodon, rabbit, guinea pig, and marmoset monkey brains: a comparative autoradiographic study. Synapse 51:249-269.

Gouarderes C, Quelven I, Mollereau C, Mazarguil H, Rice SQ, Zajac JM (2002) Quantitative autoradiographic distribution of NPFF1 neuropeptide FF receptor in the rat brain and comparison with NPFF2 receptor by using [125I]YVP and [(125I]EYF as selective radioligands. Neuroscience 115:349-361.

Henriques MG, Silva PM, Martins MA, Flores CA, Cunha FQ, Assreuy-Filho J, Cordeiro RS (1987) Mouse paw edema. A new model for inflammation? Braz J Med Biol Res 20(2):243-249.

Honore P, Rogers SD, Schwei MJ, Salak-Johnson JL, Luger NM, Sabino MC, Clohisy DR, Mantyh PW (2000) Murine models of inflammatory, neuropathic and cancer pain each generates a unique set of neurochemical changes in the spinal cord and sensory neurons. Neuroscience 98:585-598. 
Kersante F, Mollereau C, Zajac JM, Roumy M (2006) Anti-opioid activities of NPFF1 receptors in a SH-SY5Y model. Peptides 27:980-989.

Kimura M, Satoh T, Matsumoto N (2007) What does the habenula tell dopamine neurons? Nature Neurosci 10:677-678.

Kornetsky C, Huston-Lyons D, Porrino LJ (1991) The role of the olfactory tubercle in the effects of cocaine, morphine and brain-stimulation reward. Brain Res 541:75-81.

Kotlinska J, Pachuta A, Dylag T, Silberring J (2007) Neuropeptide FF (NPFF) reduces the expression of morphine- but not of ethanol-induced conditioned place preference in rats. Peptides 28:2235-2242.

Kowianski P, Morys JM, Wojcik S, Dziewiatkowski J, Luczynska A, Spodnik E, Timmermans JP, Morys J (2004) Neuropeptide-containing neurons in the endopiriform region of the rat: morphology and colocalization with calcium-binding proteins and nitric oxide synthase. Brain Res 996:97-110.

Lombard MC, Weil-Fugazza J, Ries C, Allard M (1999) Unilateral joint inflammation induces bilateral and time-dependent changes in neuropeptide FF binding in the superficial dorsal horn of the rat spinal cord: implication of supraspinal descending systems. Brain Res 816:598-608.

Malin DH, Lake JR, Fowler DE, Hammond MV, Brown SL, Leyva JE, Prasco PE, Dougherty TM (1990) FMRF-NH2-like mammalian peptide precipitates opiate-withdrawal syndrome in the rat. Peptides 11:277-280.

Mantyh PW (2004) A mechanism-based understanding of bone cancer pain. Novartis Foundation symposium 261:194-214; discussion 214-199, 256-161.

Mantyh PW, Clohisy DR, Koltzenburg M, Hunt SP (2002) Molecular mechanisms of cancer pain. Nature Rev Cancer 2:201-209.

Mao-Ying QL, Cui KM, Liu Q, Dong ZQ, Wang W, Wang J, Sha H, Wu GC, Wang YQ (2006) Stage-dependent analgesia of electro-acupuncture in a mouse model of cutaneous cancer pain. European J Pain 10:689-694.

Marchand S, Betourne A, Marty V, Daumas S, Halley H, Lassalle JM, Zajac JM, Frances B (2006) A neuropeptide FF agonist blocks the acquisition of conditioned place preference to morphine in C57BI/6J mice. Peptides 27:964-972.

Menendez L, Lastra A, Fresno MF, Llames S, Meana A, Hidalgo A, Baamonde A (2003) Initial thermal heat hypoalgesia and delayed hyperalgesia in a murine model of bone cancer pain. Brain Res 969:102-109.

Mercadante S (2001) Recent progress in the pharmacotherapy of cancer pain. Expert Rev Anticancer Ther 1:487-494.

Miller CA, Marshall JF (2005) Molecular substrates for retrieval and reconsolidation of cocaineassociated contextual memory. Neuron 47:873-884.

Narita M, Kaneko C, Miyoshi K, Nagumo Y, Kuzumaki N, Nakajima M, Nanjo K, Matsuzawa K, Yamazaki M, Suzuki T (2006) Chronic pain induces anxiety with concomitant changes in opioidergic function in the amygdala. Neuropsychopharmacology 31:739-750.

Narita M, Kishimoto Y, Ise Y, Yajima Y, Misawa K, Suzuki T (2005) Direct evidence for the involvement of the mesolimbic kappa-opioid system in the morphine-induced rewarding effect under an inflammatory pain-like state. Neuropsychopharmacology 30:111-118.

Narita M, Nakamura A, Ozaki M, Imai S, Miyoshi K, Suzuki M, Suzuki T (2008) Comparative Pharmacological Profiles of Morphine and Oxycodone under a Neuropathic Pain-Like State in Mice: Evidence for Less Sensitivity to Morphine. Neuropsychopharmacology 33:1097-112.

Nystedt JM, Lemberg K, Lintunen M, Mustonen K, Holma R, Kontinen VK, Kalso E, Panula P (2004) Pain- and morphine-associated transcriptional regulation of neuropeptide FF and the G-protein-coupled NPFF2 receptor gene. Neurobiol Dis 16:254-262. 
Ozaki S, Narita M, Narita M, lino M, Miyoshi K, Suzuki T (2003) Suppression of the morphineinduced rewarding effect and G-protein activation in the lower midbrain following neve injury in the mouse: involvement of G-protein-coupled receptor kinase 2. Neuroscience 116:89-97.

Ozaki S, Narita M, Narita M, lino M, Sugita J, Matsumura Y, Suzuki T (2002) Suppression of the morphine-induced rewarding effect in the rat with neuropathic pain: implication of the reduction in mu-opioid receptor functions in the ventral tegmental area. $\mathrm{J}$ Neurochem 82:1192-1198.

Ozaki S, Narita M, Narita M, Ozaki M, Khotib J, Suzuki T (2004) Role of extracellular signalregulated kinase in the ventral tegmental area in the suppression of the morphineinduced rewarding effect in mice with sciatic nerve ligation. J Neurochem 88:1389-1397.

Passik SD, Kirsh KL, Donaghy KB, Portenoy RK (2006) Pain and aberrant drug-related behaviors in medically ill patients with and without histories of substance abuse. Clin $\mathrm{J}$ Pain 22:173-181.

Porter J, Jick H (1980) Addiction rare in patients treated with narcotics. N Engl J Med 302:123.

Ronson A (2004) Psychiatric disorders in oncology: recent therapeutic advances and new conceptual frameworks. Curr Opin Oncol 16:318-323.

Roques BP (2000) Novel approaches to targeting neuropeptide systems. Trends Pharmacol Sci $21: 475-483$.

Roumy M, Zajac JM (1998) Neuropeptide FF, pain and analgesia. Eur J Pharmacol 345:1-11.

Sallerin-Caute B, Lazorthes Y, Deguine O, Frances B, Verdie JC, Charlet JP, Bastide R (1998) Does intrathecal morphine in the treatment of cancer pain induce the development of tolerance? Neurosurgery 42:44-50.

Sasamura T, Nakamura S, lida Y, Fujii H, Murata J, Saiki I, Nojima H, Kuraishi Y (2002) Morphine analgesia suppresses tumor growth and metastasis in a mouse model of cancer pain produced by orthotopic tumor inoculation. Eur J Pharmacol 441:185-191.

Savage SR (1996) Long-term opioid therapy: assessment of consequences and risks. Journal Pain Symptom Manag 11:274-286.

Schwei MJ, Honore P, Rogers SD, Salak-Johnson JL, Finke MP, Ramnaraine ML, Clohisy DR, Mantyh PW (1999) Neurochemical and cellular reorganization of the spinal cord in a murine model of bone cancer pain. J Neurosci 19:10886-10897.

Shippenberg TS, Stein C, Huber A, Millan MJ, Herz A (1988) Motivational effects of opioids in an animal model of prolonged inflammatory pain: alteration in the effects of kappa- but not of mu-receptor agonists. Pain 35:179-186.

Simonin F, Schmitt M, Laulin JP, Laboureyras E, Jhamandas JH, MacTavish D, Matifas A, Mollereau C, Laurent P, Parmentier M, Kieffer BL, Bourguignon JJ, Simonnet G (2006) RF9, a potent and selective neuropeptide FF receptor antagonist, prevents opioidinduced tolerance associated with hyperalgesia. Proc Natl Acad Sci U S A 103:466-471.

Sufka KJ (1994) Conditioned place preference paradigm: a novel approach for analgesic drug assessment against chronic pain. Pain 58:355-366.

Sufka KJ, Watson GS, Nothdurft RE, Mogil JS (1998) Scoring the mouse formalin test: validation study. Eur J Pain 2:351-358.

Suzuki T (2001) Mechanism of opioid dependence and interaction between opioid receptors. Eur J Pain 5 Suppl 1:63-65.

Suzuki T, Kishimoto Y, Misawa M, Nagase H, Takeda F (1999) Role of the kappa-opioid system in the attenuation of the morphine-induced place preference under chronic pain. Life Sci 64:PL1-7.

Taraschenko OD, Shulan JM, Maisonneuve IM, Glick SD (2007) 18-MC acts in the medial habenula and interpeduncular nucleus to attenuate dopamine sensitization to morphine in the nucleus accumbens. Synapse 61:547-560. 
Tzschentke TM (1998) Measuring reward with the conditioned place preference paradigm: a comprehensive review of drug effects, recent progress and new issues. Prog Neurobiol 56:613-672.

Tzschentke TM (2007) Measuring reward with the conditioned place preference (CPP) paradigm: update of the last decade. Addict Biol 12:227-462.

Wacnik PW, Eikmeier LJ, Ruggles TR, Ramnaraine ML, Walcheck BK, Beitz AJ, Wilcox GL (2001) Functional interactions between tumor and peripheral nerve: morphology, algogen identification, and behavioral characterization of a new murine model of cancer pain. $J$ Neurosci 21:9355-9366.

Yang HY, ladarola MJ (2003) Activation of spinal neuropeptide FF and the neuropeptide FF receptor 2 during inflammatory hyperalgesia in rats. Neuroscience 118:179-187.

Yang HY, ladarola MJ (2006) Modulatory roles of the NPFF system in pain mechanisms at the spinal level. Peptides 27:943-952.

Zajac JM (2001) Neuropeptide FF: new molecular insights. Trends Pharmacol Sci 22:63.

Zimmermann M (1983) Ethical guidelines for investigations of experimental pain in conscious animals. Pain 16:109-110. 
Tables: none

Figures: 6 
Figure Legends

Figure 1a

Evolution of the oedema on the injected hind paws. Carrageenan, Complete Freund's Adjuvant and melanoma cells were injected at Day 0 and the volume of the oedema was evaluated by a plethysmometer. Each point represents the mean paw volume $(\mathrm{ml})+/-$ S.E.M of 8 to 14 animals. The nociceptive behaviour and Conditioned Place Preference have been measured at the acme of pain, indicated for each case by a line with four bars (D1 to D4).

Figure $1 b$

Picture illustrating the lateral aspect of the hind paws, 21 days after $\mathrm{NaCl}$ injection $(\mathrm{A})$ or inoculation of melanoma cells $(B)$.

Figure 2

Evolution of the spontaneous nociceptive behaviour: injected hind paw lickings.

The nociceptive behavior was evaluated by counting injected-paw lickings during the 20 minutes of behavioural testing across the four days (D1 to D4) of place conditioning. Data are expressed as the mean of paw lickings +/- S.E.M.

Figure 3

Evolution of the nociceptive behavior: horizontal locomotion

a- Locomotor activity evaluated was for each mouse by the number of crossings of the experimental chamber. This measure was performed during the two alternate conditioning sessions on Day 1, i.e. after the i.p. injection of morphine (10 mg. $\mathrm{kg}^{-1}$, closed bars) and after the injection of $\mathrm{NaCl}(0.9 \%$, open bars). 
${ }^{* *} p<0.01$ and ${ }^{* * *} p<0.001$ ANOVA followed by a LSD post-hoc analysis for the suffering mice vs control animals after the injection of $\mathrm{NaCl}$;

${ }^{\# \#} p<0.01$ and ${ }^{\# \#} p<0.001$ ANOVA followed by a LSD post-hoc analysis for the suffering mice vs control animals after morphine injection;

${ }^{++} p<0.001$ and ${ }^{+} p<0.05$, locomotor activity within groups (paired Student t-Test).

b- Locomotor activity was evaluated in the absence of morphine, on Day 0 (preconditioning) and after conditioning during the final test on Day 4.

${ }^{\#} p<0.05$ and ${ }^{\# \#} p<0.01$ ANOVA followed by a LSD post-hoc analysis for the suffering mice vs control animals on Day 4;

${ }^{+} p<0.05, \mathrm{D} 4$ vs D0 within groups (paired Student t-Test).

Figure 4:

Both chronic inflammatory pain and cancer pain suppress morphine-induced Conditioned Place Preference. Data (mean +/- S.E.M.) represent the time (sec) spent in the drug-paired compartment before (open bars) and after (closed bars) conditioning mice with i.p. morphine injections $\left(10 \mathrm{mg}^{\mathrm{kg}}{ }^{-1}\right)$.

${ }^{*} p<0.05$ and ${ }^{* *} p<0.005$, D4 vs D0 within groups (paired Student t-Test).

Figure 5

Distribution of $\left[{ }^{125 l}\right]$ EYF binding to NPFF2 receptors in various brain regions of control, carrageenan, and cancer mice. Results are expressed as mean +/- S.E.M. of binding values (PSL/pixel) calculated from several determinations from 4 to 6 animals per group. 
${ }^{*} p<0.05$, significant differences between groups, ANOVA followed by a LSD post-hoc analysis.

Figure 6

Comparative autoradiographic localization of $\mathrm{NPFF}_{2}$ receptors in representative rostrocaudal coronal brain sections (ranging from bregma 4.28 to bregma -3.4 ) from control, carrageenan and cancer groups. Images show total $\left[{ }^{125} \mathrm{I}\right] \mathrm{EYF}(0.05 \mathrm{nM})$ binding after 5 days phosphorscreen imaging plate exposure. The non-specific binding assessed with $1 \mu \mathrm{M}$ NPFF was close to background labelling level. 
Fig.1a

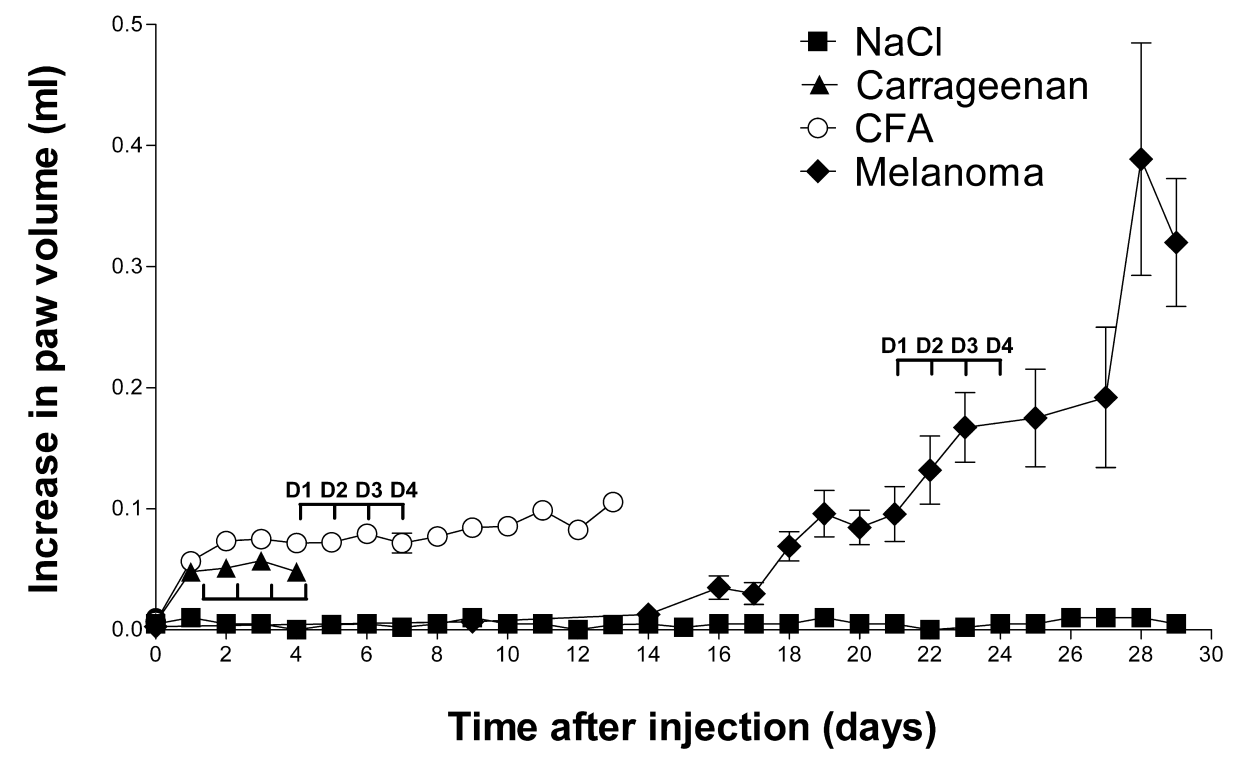




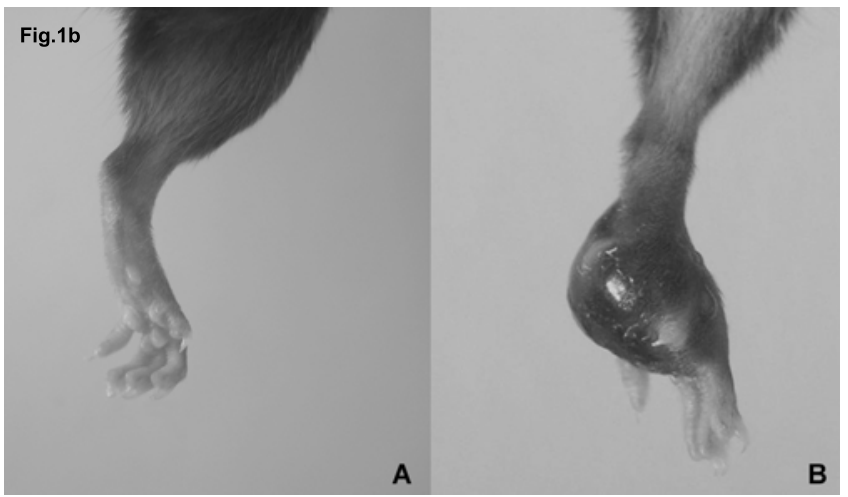




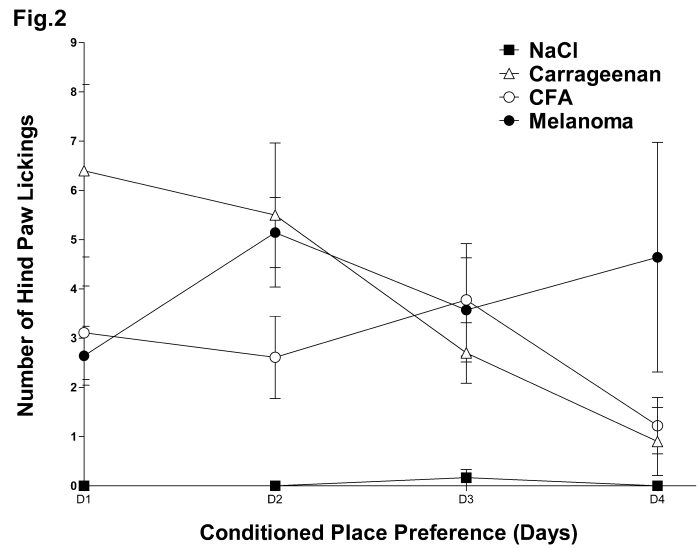


Hii 


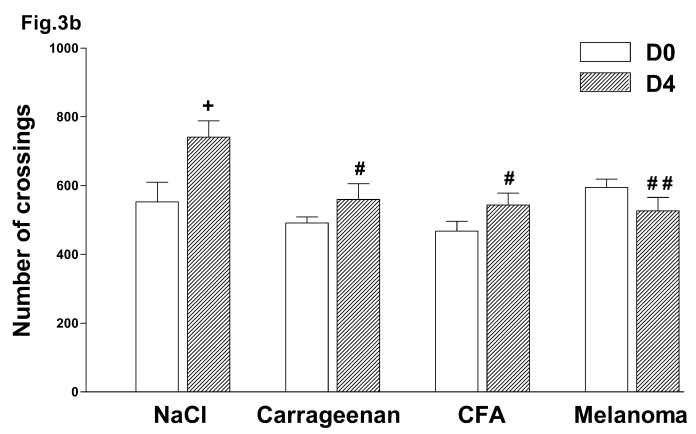


Fig.4

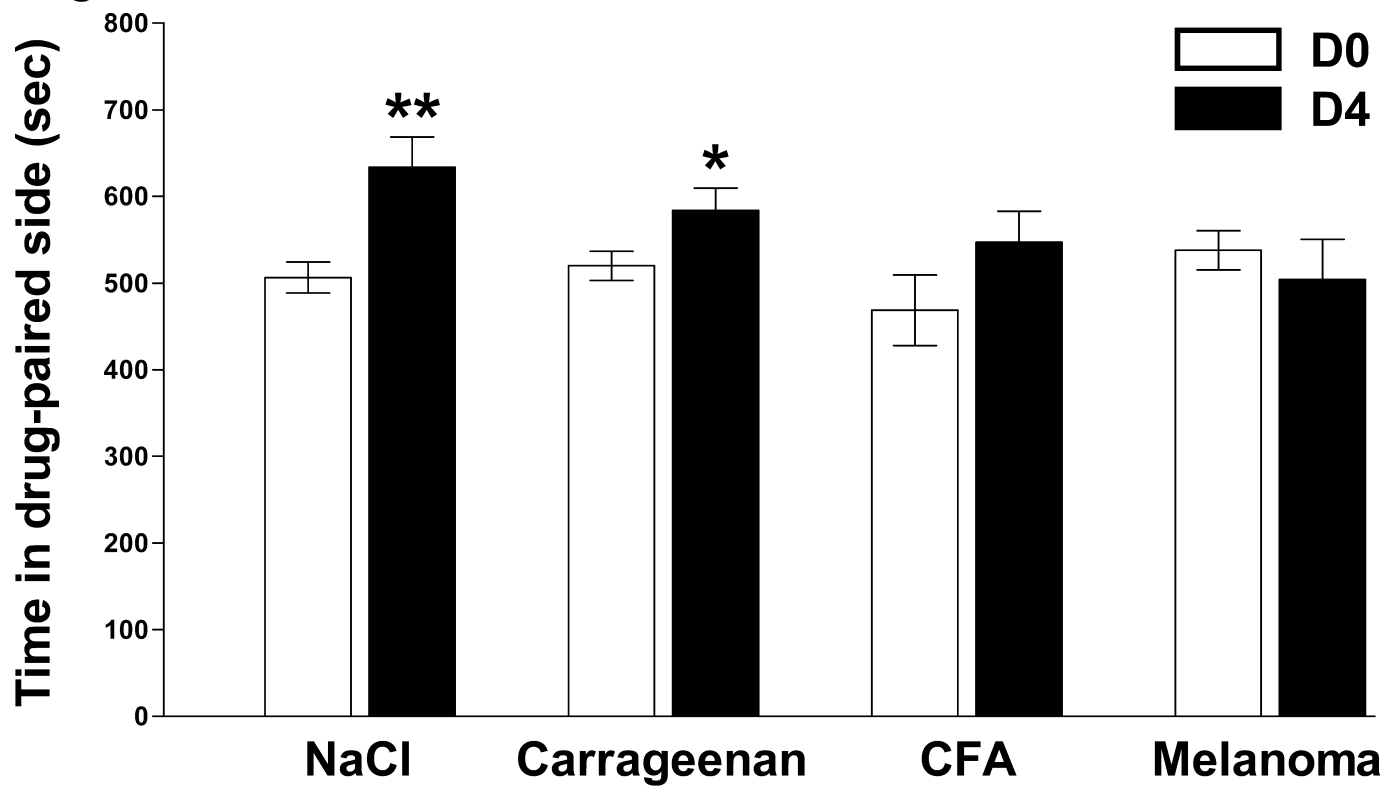




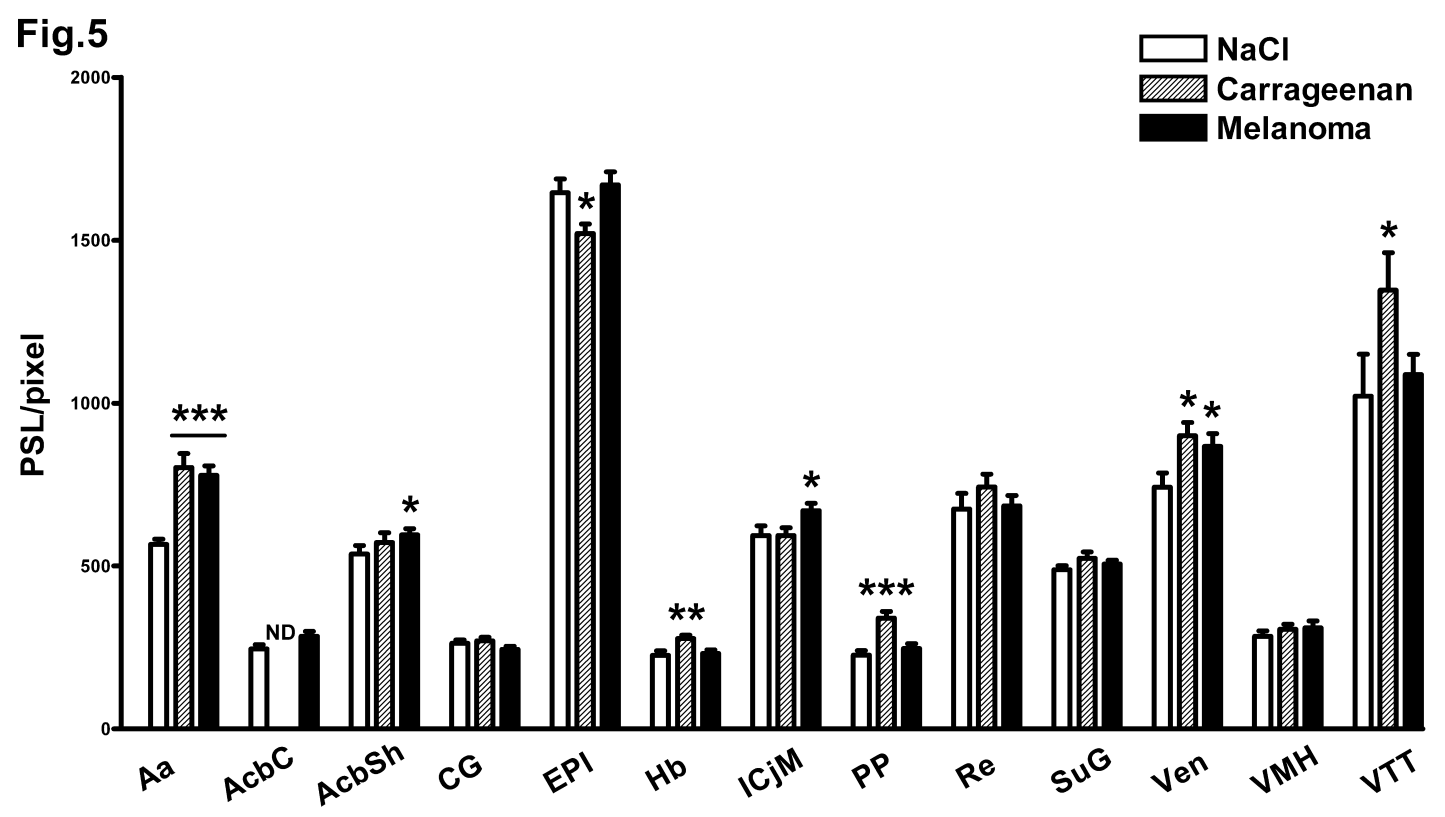




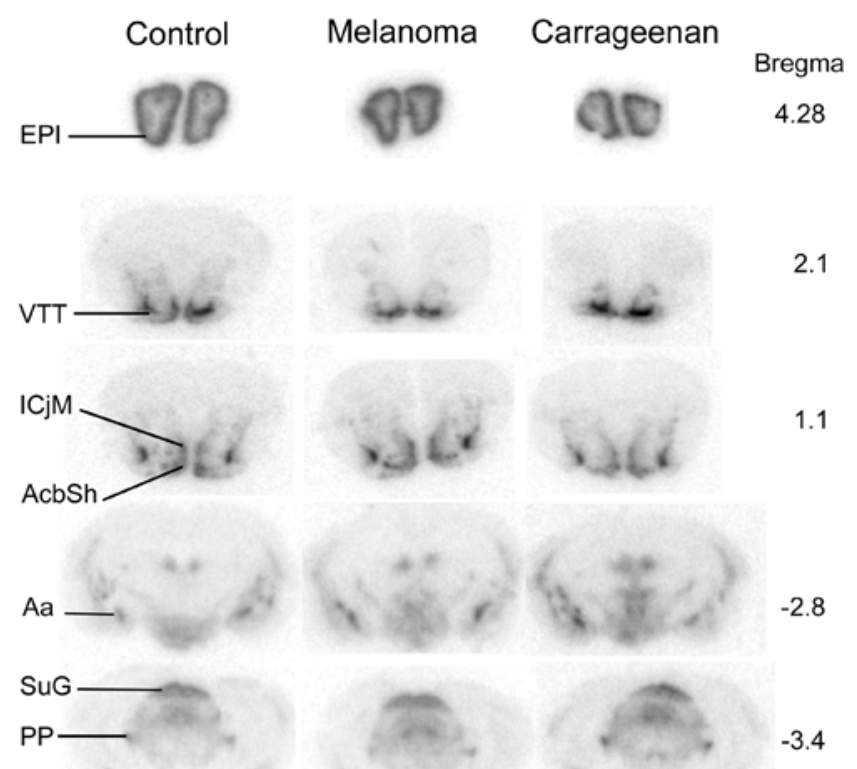

